\title{
The effect of humidity on peak value of HEMA carbonyl absorbance band
}

\author{
Adioro Soetojo \\ Department of Conservative Dentistry \\ Faculty of Dentistry Airlangga University \\ Surabaya - Indonesia
}

\begin{abstract}
Bond strength between 2-Hydroxyethyl methacrylate HEMA-based dentin bonding agent and dentin collagen had proved by presence of the chemical interaction. This union involved the carbonyl group on HEMA resin with amino group on dentin collagen following produce an amide chain. However, this bond strength influence by humidity condition of dentin collagen and HEMA resin. The aim of this study is to measure the effect of humidity on peak value of the HEMA carbonyl absorbance band. The bond strength between by HEMA bonding agent and dentine collagen was analyzed in different humidity, e.g. in 60\%, 70\%, 80\%, and 90\% humidity. Control experiment was done in ambient room humidity that is $65 \%$. Chemical bond that formed between HEMA and dentine collagen was carried out by mixing pure HEMA with bovine type-I collagen which had been stored in different humidity. The esther carbonyl group of HEMA will react with the amino group of collagen, produced an amide bonding, which is observed by measuring the IR spectrum absorbance of the esther carbonyl group of HEMA in KBr method. The decrease of the carbonyl group absorbance indicates the more chemical bonds formed. By measuring the absorbance of $C=O$ esther in different humidity, it showed that the greatest number of chemical bonds resulted when the experiment was done in $70 \%$ humidity condition.
\end{abstract}

Key words: humidity, FTIR, HEMA, carbonyl group, type-I dentine collagen

Correspondence: Adioro Soetojo, c/o: Bagian Konservasi Gigi, Fakultas Kedokteran Gigi Universitas Airlangga. Jln. Mayjend. Prof. Dr. Moestopo No. 47 Surabaya 60132, Indonesia.

\section{INTRODUCTION}

The 2-hydroxyethyl methacrylate (HEMA) is often used as liquid base of dentine bonding. ${ }^{1,2,3}$ Several reports claims that HEMA has a good physical and chemical characteristic. ${ }^{4-7}$ The 2-hydroxyethyl methacrylate bind to dentine surface by chemical or mechanical bond. Chemical bond of HEMA to dentine collagen is covalent bond or primary bond between atoms. Covalent bond between nitrogen atom of collagen and carbon atom of resin aldehyde will form in chemical interaction. ${ }^{3} \mathrm{Xu}$ et al. ${ }^{4}$ reported that by F-T Raman spectroscopy, if there are new bonding, for example $\mathrm{C}-\mathrm{N}$ of $\mathrm{C}=\mathrm{O}$ at esther group of HEMA, hence will yield product of amide [C(O)NH].

Clinically, one of total etched technique step is wash and dries the dentin surface. The purpose of washing step is to discard salt formed as reaction of acid etched materials and dentin minerals. The drying procedure will remove excess water that are used for washing dentin surface after etching process. ${ }^{1,2,3}$ Many researchers said that at the time of drying procedure, the dentin surface should neither too dry nor wet. ${ }^{4,7}$ If the surface is too dry, the dentin collagen will collapse. However, if the surface is too wet, there are many water molecules around collagen hence yield hydrogen bond between water and amino collagen. With this phenomenon, dentin bonding agents will not bond to dentin collagen network carefully. So we need an optimal condition (optimal humidity) on dentin surface to obtain a maximal bonding between dentin bonding materials and dentin collagen.

Besnault and $\mathrm{Attal}^{8}$ expressing that at $50 \%$ and $60 \%$ humidity, bond strength of bonding materials at dentine is higher than at $80 \%$ and $90 \%$ humidity. At the minimum humidity, the amount of water around dentine is optimal. Water molecules can form hydrogen bond with collagen peptide, and then break hydrogen bond between molecules of fibril collagen. At drying procedure, fibrils will re-expansion again after collapse.

Kemp 9 reported that HEMA carbonyl when reacting with amino collagen group, peak reduction of the mixture esther carbonyl and HEMA with collagen will happened at infra red spectrum. It can be assumed that there are many groups of carbonyl esther bonding with amino if there is a high peak reduction of HEMA carbonyl absorbance band. This means chemical bond between HEMA and collagen become stronger.

The purpose of this research is to know the effect of humidity on peak value of the HEMA carbonyl absorbance band. In knowing, the smallest value of HEMA carbonyl absorbance band will also know the chemical bond strength between HEMA and dentine collagen maximally at optimal humidity. 


\section{MATERIALS AND METHODS}

This research is an experimental laboratory research. ${ }^{10,11}$ Bovine incisive were obtained from animal slaughtering house at Jl. Pegirian Surabaya. After cleaning, tooth was soaked in physiological salt solution and kept in refrigerator (temperature $4^{\circ} \mathrm{C}$ ). Pure bovine type I collagen and HEMA pure liquid were purchased from Sigma Chemical, St. Louis, USA. Appliances that were used: desiccators with vacuum faucet (China), hygrometer (Haar. Synth. Hygro, Germany), air suction (Schuco, USA), and FTIR (Jasco FT / IR 5300, Japan).

To arrange $90 \%$ humidity, $150 \mathrm{cc}$ of water were putted at the bottom part of desiccators then put hygrometer that have been calibrated. At this condition humidity which seen at hygrometer was range from 94 to $95 \%$. Hereafter from faucet located above desiccators, air pumped out by air suction until reach humidity $90 \%$ and closed the faucet. For humidity $80 \%$, air inside the desiccators were pumped out until reach humidity $80 \%$. To quicken the process, put silica gel that activated before in the desiccators. Same process was done for $70 \%$ and $60 \%$ humidity.

To make $\mathrm{KBr}$ pellets, $300 \mathrm{mg} \mathrm{KBr}$ powder (bromide kalium) was prepared, then $10 \mu \mathrm{l}(10,7 \mathrm{mg}$ weight $)$ of HEMA (1,07 g/ml) were dropped using micro-pipette. $\mathrm{KBr}$ powder and HEMA (310,7 mg ) were crushed with mortal and pestle. Some part of this mixture $(50 \mathrm{mg})$ were put into $\mathrm{KBr}$ die appliance then were compressed and vacuuming by compressor until 10 ton. This vacuuming and compressing process was done in 5-10 minutes. The obtained result was a transparent pellet (form like thin tablet). The pellets were observed into Fourier Transform Infrared Spectroscopy (FTIR) appliance. These samples were control samples. Room humidity was $65 \%$ and room temperature was $25^{\circ} \mathrm{C} \pm 2^{0} \mathrm{C}$.

To make a mixture of collagen sample and HEMA, 10 $\mu \mathrm{l}(10,7 \mathrm{mg}$ ) HEMA was dropped to collagen $(2 \mathrm{mg})$, then $\mathrm{KBr}$ powder were added till the weight of the mixtures were $310,7 \mathrm{mg}$. The mixture of this materials were crushed, $50 \mathrm{mg}$ of them were put into KBR die, then compressed and vacuumed until 10 ton. The pellets were observed into FTIR appliance.

To make sample for the group of treatment by different humidity, $2 \mathrm{mg}$ collagen fibers were packed into desiccators with hygrometer appliance that have been calibrated. Then desiccator's humidity was arranged to $60 \%, 70 \%, 80 \%$ and $90 \%$.

As soon as released from desiccators, HEMA and $\mathrm{KBr}$ powder were added on collagen until $310,7 \mathrm{mg}$ in weight. The mixtures were crushed, $50 \mathrm{mg}$ of them were, compressed and vacuumed until 10 ton and pellets were made in the same method, which has been explained above. In this study, each sample group was conducted until three times research ( $\mathrm{n}=3$ to each group). The measuring was conducted at peak value of carbonyl absorbance band $(\mathrm{C}=\mathrm{O})$ of treatment group which was compared to control group. The method to calculate peak value of carbonyl absorbance band $(\mathrm{P})$ as follows: ${ }^{9}$

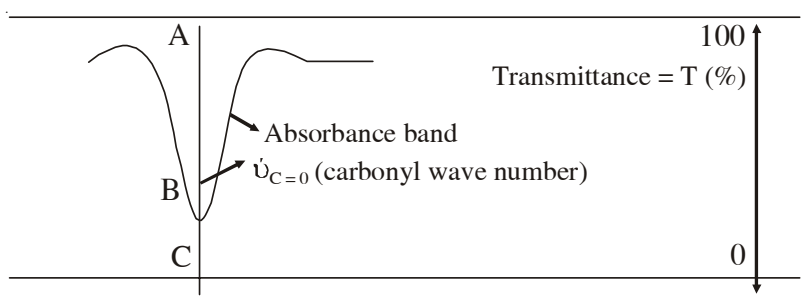

Figure 1. Peak of the HEMA carbonyl absorbance band.

Description:

$\mathrm{P}=(\mathrm{BC} / \mathrm{AB}) \mathrm{X} 100 ; \mathrm{AB}, \mathrm{BC}$ measured in centimeters.

This calculation is accurate enough and can be trusted if absorbance band intensity at $\mathrm{T}$ : $30-60 \%$.

Figure 2 and 3 shows peak value of carbonyl absorbance band at various humidity:

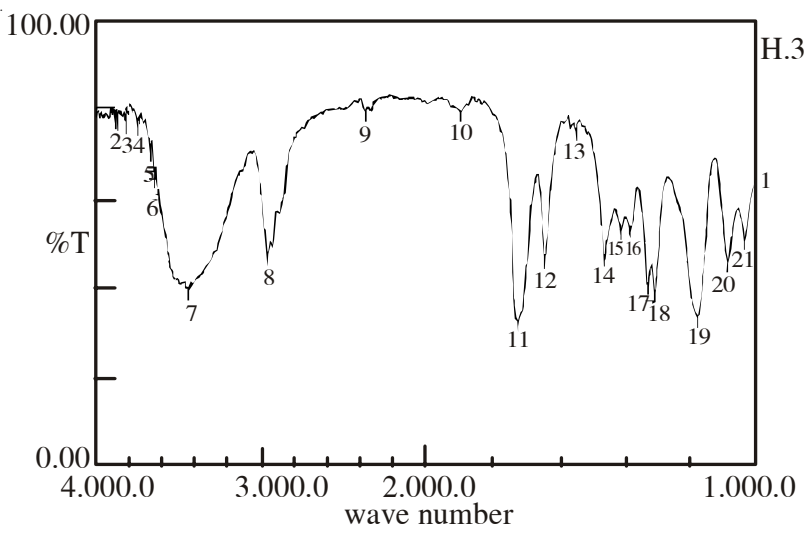

Figure 2. Infrared Spectrum of pure HEMA ( $\mathrm{KBr}$ pellet) Peak value of carbonyl absorbance band is 46.1 (number 11)

Wave number $(\mathrm{C}=\mathrm{O})$ at $1720 \mathrm{~cm}^{-1}$, T value: $\pm 80 \%$.

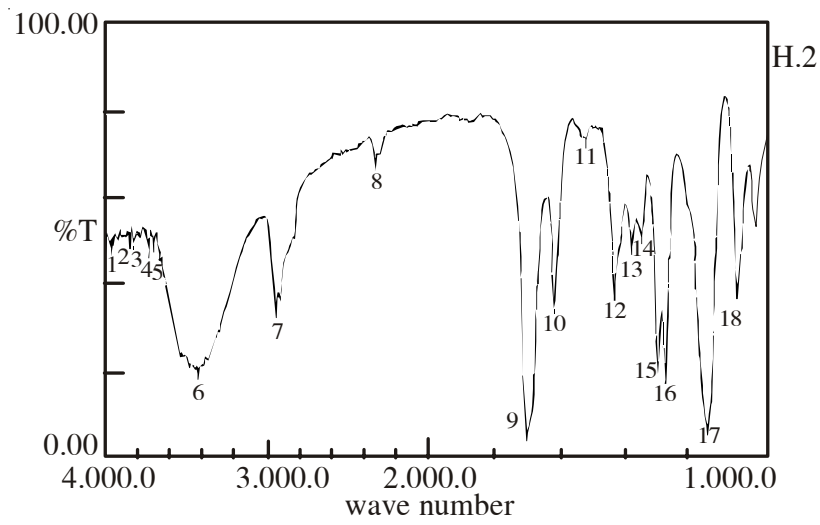

Figure 3. Infrared Spectrum of HEMA + Collagen ( $\mathrm{KBr}$ pellet) Peak value of carbonyl absorbance band is 9.8 (number 9)

Wave number $(\mathrm{C}=\mathrm{O})$ at $1720 \mathrm{~cm}^{-1}$, $\mathrm{T}$ value: $\pm 50 \%$ 


\section{RESULTS}

Principally, the peak value of HEMA carbonyl absorbance band will decreased if many groups of HEMA carbonyl bind with groups of amino at dentin collagen,. This matter designate that many groups of carbonyl are bonding with groups of amino, thus it means chemical bond between HEMA and collagen is strong.

Mean value of the HEMA carbonyl absorbance band and standard deviation were shown at table 1.

Table 1. Mean value of peak of HEMA carbonyl absorbance band at various humidity

\begin{tabular}{cccc}
\hline Humidity & $\mathrm{N}$ & $\overline{\mathrm{X}}($ mean $)$ & $\mathrm{SD}$ \\
\hline HEMA & 3 & $47.5667^{\mathrm{a}}$ & 5.6448 \\
$60 \%$ & 3 & $21.2000^{\mathrm{b}}$ & 8.8606 \\
$70 \%$ & 3 & $9.5000^{\mathrm{c}}$ & 2.9614 \\
$80 \%$ & 3 & $29.0000^{\text {bdf }}$ & 6.3553 \\
$90 \%$ & 3 & $32.2667^{\text {de }}$ & 3.2083 \\
$65 \%$ & 3 & $19.7333^{\text {bcdf }}$ & 6.6214 \\
\hline
\end{tabular}

Description:

$\mathrm{N} \quad=$ amount of sample

$\overline{\mathrm{X}} \quad=$ mean value of peak HEMA carbonyl absorbance band

$\mathrm{SD} \quad=$ standard deviation

ANOVA F $=14.257, \mathrm{p}>0.001$

Superscript with different letter showed there significances at $=0.05$

Pure HEMA have peak carbonyl absorbance band equal to $47.5 \pm 5.6$, then the peak value decreased at $60 \%, 65 \%$, and $70 \%$ humidity, the value was $21.2 \pm 8.8 ; 19.7 \pm 6.6$ and $9.5 \pm 2.9$ respectively. This result mean at the lowest humidity, the bonding between HEMA carbonyl group and amino collagen group will increase. In the other hand, bonding between HEMA carbonyl group and amino collagen decreased at $80 \%$ and $90 \%$ humidity, where the peak of absorbance band was at $29.0 \pm 6.3$ and $32.3 \pm 3.2$.

To know that the measurement data chemically is normal, Normal Distribution test was done. P value of entire group treatment of $60-90 \%$ humidity shows the higher number than $0.05(\mathrm{p}>0.05)$. This means group data attempt of chemical bond at $60-90 \%$ humidity is normal distribution.

Next, homogeneity test was conducted to prove whether the treatment chemical sample group is homogenous, hence from calculation obtained by value of $\mathrm{p}=0.460(\mathrm{p}>0.05)$ meaning chemical sample group at $60-90 \%$ humidity was homogeneous.

By ANOVA Test, effect of 60-90\% humidity to chemical bond between HEMA and dentine collagen shows the significant difference for each sample group $(\mathrm{p}<0.05)$. The significance of each chemical sample group at 60-90\% humidity was calculated with LSD Test.

The result has shown a significant difference between peak value of pure HEMA carbonyl absorbance band and HEMA carbonyl absorbance band at $60 \%$ humidity $(p<0.05)$. There is a significant difference between pure
HEMA and group at $70 \%, 80 \%, 90 \%$, and $65 \%$. There was no significant difference between group at $60 \%$ and $65 \%$, and $80 \%$ humidity $(\mathrm{p}>0.05)$.

There was a significant difference between group at $70 \%$ humidity and sample group of $60 \%, 80 \%$, and $90 \%$ humidity $(\mathrm{p}<0.05)$, but if compared with group at $65 \%$ humidity (control), there was no significant difference.

Furthermore, there was a significant difference between group at $80 \%$ humidity and $70 \%$ humidity, but there was no difference significance between group at $80 \%$ humidity and group of humidity 60\%, 90\%, and 65\% (control). Group at $90 \%$ humidity showed a significant difference if compared with group at $60 \%$ and $65 \%$.

\section{DISCUSSION}

Some expert expressed that chemical interactions between HEMA and dentine collagen is through reaction between HEMA carbonyl group and amino dentine collagen group. Bonding between amino collagen $\left(\mathrm{NH}_{2}\right)$ group and HEMA carbonyl group is only some of all chemical bond that possibly happened. This reaction form the new formation that are an amide bonding and also the side effect in the form of etilen-glikol. ${ }^{4}$

Renzo and Ellis ${ }^{12}$ stated chemical bond between dentin and HEMA happened as result of reaction between resin and collagen function group, for example carboxylate, hydroxyl, amine group, or amide. Could also happened complex reaction with ion of $\mathrm{Ca}^{++}$of hydroxy-apatite.

Wang and Spencer ${ }^{13}$ that investigating chemical interaction between HEMA and Bis-GMA at dentin surface, obtained that penetrating of HEMA into dentin surface which forming hybrid layer can reach until $10 \mu \mathrm{m}$. At this depth, penetration of HEMA is decreased until remain $8.85 \%$. They used spectroscopy of micro-Raman and absorbance band which are observed was carbonyl absorbance band $\left(1720 \mathrm{~cm}^{-1}\right), \mathrm{C}=\mathrm{C}$ phenyl $\left(1609 \mathrm{~cm}^{-1}\right)$, group of $\mathrm{CH} 2\left(1453 \mathrm{~cm}^{-1}\right)$ and others.

Bonding of HEMA resin at dentine collagen also depend on to the number of hydrogen bonds. ${ }^{6}$ If there are any resistance of carboxylic acid dissociation or amino collagen group hence will improve hydrogen bond between HEMA resin and dentine collagen. Previously, they studied the absorption of HEMA resin at dentine collagen characteristically by C-NMR. ${ }^{12}$ The reduction of $\mathrm{T}_{1}$ value of HEMA carbonyl esther carbon is bigger than at other carbon, which estimated will form hydrogen bond between HEMA carbonyl ester and dentine collagen. The amount of HEMA concentrations in solution and HEMA adsorption into collagen has correlation with tensile bond strength of resin at dentine.

In present chemically research, pure HEMA is used to directly knowing the role of HEMA to chemical bond with pure collagen. Mean average peak value of pure HEMA carbonyl absorbance band was equal to $47.5 \pm 5$.6. Thus at $60 \%, 65 \%$, and $70 \%$ humidity, the peak value decreased 
significantly to $21.2 \pm 8.8,19.7 \pm 6.6$, and $9.5 \pm 2.9$. It means that the amount of HEMA carbonyl group, which is bonding with amino collagen group, is increase at $60 \%$, $65 \%$, and $70 \%$ humidity. The tensile bond strength of HEMA with collagen also increase and the highest tensile bond strength obtained at $70 \%$ humidity. At $70 \%$ humidity the water condition around fibril is very optimal in causing chemical interaction between HEMA and collagen. Water could make collagen to re-expansion, thus the fibril are more active and permeable to HEMA resin.

At $80 \%$ and $90 \%$ humidity, the chemical bond between HEMA resin and collagen was decreased significantly (peak value of carbonyl absorbance band at $80 \%$ humidity: $29.0 \pm 6.3 ; 90 \%$ humidity: $32.3 \pm 3.2$ ). The increasing amount of water molecules around collagen will block the penetration of HEMA materials to collagen fibril. The increasing of water amount around collagens will also increase hydrogen bonding between water and HEMA carbonyl group. The increase of this hydrogen bonding will block the bonding between HEMA and collagen, so it will decrease the amount of HEMA carbonyl group which is bonding to amino collagen and also decreasing the tensile bond strength. This situation is according to statement of Nakabayashi and Pashley. ${ }^{7}$

The difficulty to obtain good sample was also explained by Wang and Spencer. ${ }^{13}$ They said that absolute intensity of Raman absorbance band depend on some factors: softness of sample surface, focusing position, detection depth, fluorescence biological component, equipments stability, and the power of laser-ray. For each sample, the result of absorbance band intensity will differ at the time of measurement, even for the same area of spot at one sample.
This research demonstrated that $70 \%$ humidity is the most optimal humidity to get maximal chemical bond between HEMA carbonyl group and dentine collagen amino.

\section{REFERENCES}

1. Craig RG, Powers JM, Wataha JC. Dental materials. Properties and manipulation. $8^{\text {th }}$ ed. Baltimore, Boston, Carlsbad: Mosby Inc; 2002. p. 57-78.

2. Noort RV. Introduction to dental materials. $2^{\text {nd }}$ ed. Edinburgh, London, New York, Oxford: CV Mosby Co; 2002. p. 11-78.

3. Anusavice KJ. Phillip's science of dental materials. $11^{\text {th }}$ ed. Philadelphia, London, Toronto: WB Saunders Co; 2003. p. 21-395.

4. Xu J, Stangel I, Butler IS, Gilson DFR. An FT Raman spectroscopy investigation of dentin and collagen surfaces modified by HEMA. J Dent Res 1997; 76:596-601.

5. Finger WJ, Tani C. Effect of relative humidity on bond strength of self-etching adhesive to dentin. J Adhes Dent 2002; 4:277-82.

6. Nishiyama N, Suzuki K, Nagatsuka A, Nemoto K. Dissociation states of collagen functional groups and their effects on priming efficacy of HEMA bonded to collagen. J Dent Res 2003; 82:257-61.

7. Nakabayashi NP, Pashley DH. Hybridization of dental hard tissues. $1^{\text {st }}$ ed. Chicago IL: Quintess Publ Co, Ltd; 1998. p. 1-107.

8. Besnault C, Attal JP. Influence of a simulated oral environmental on dentin bond strength of two adhesive systems. Am J Dent 2001; 14:367-72.

9. Kemp W. Organic spectroscopy. $2^{\text {nd }}$ ed. Edinburgh: ELBS/Macmillan Ltd; 1988. p. 12-81.

10. Pratiknya AW. Metodologi penelitian kedokteran dan kesehatan. Edisi ke-4. Jakarta: PT Raja-Gratindo Persada; 2001. h. 19-174.

11. Notoatmodjo S. Metodologi penelitian kesehatan. Edisi ke-2. Jakarta: PT Rineka Cipta; 2002. h. 36-202.

12. Renzo MD, Ellis TH. Chemical reactions between dentin and bonding agents. J Adhes Dent 1994; 47:115-21.

13. Wang Y, Spencer P. Hybridization efficiency of the adhesive/dentin interface with wet bonding. J Dent Res 2003; 82:141-45. 